\title{
An assessment of the strength of knots and splices used as eye terminations in a sailing environment
}

\author{
K.A. Milne and A.J. McLaren \\ Department of Mechanical Engineering, University of Strathclyde, Glasgow, UK
}

\begin{abstract}
Research into knots, splices and other methods of forming an eye termination has been limited, despite the fact that they are essential and strongly affect the performance of a rope. The aim of this study was to carry out a comprehensive initial assessment of the breaking strength of eye terminations commonly used in a sailing environment, thereby providing direction for further work in the field.

Supports for use in a regular tensile testing machine were specially developed to allow individual testing of each sample and a realistic spread of statistical data to be obtained. Over 180 break tests were carried out on four knots (the bowline, double bowline, figure-of-eight loop and perfection loop) and two splices (three-strand eye splice and braid-on-braid splice). The factors affecting their strength were investigated. A statistical approach to the analysis of the results was adopted.

The type of knot was found to have a significant effect on the strength. This same effect was seen in both types of rope construction (three-strand and braid-on-braid). Conclusions were also drawn as to the effect of splice length, eye size, manufacturer and rope diameter on the breaking strength of splices. Areas of development and further investigation were identified.
\end{abstract}

Keywords: break, knot, rope, sailing, splice, strength

\section{Introduction}

Ropes are widely exploited in sailing. Their use on yachts may be broadly divided into two categories, namely the standing and running rigging. Standing rigging consists of the structural components that support the mast and spars, together with equipment

Correspondence address:

Dr. A.J. McLaren

Department of Mechanical Engineering

University of Strathclyde

Glasgow

UK

Tel: +44 (0) 1415483104

E-mail: andrew.mclaren@strath.ac.uk such as guard rails which are present for reasons of safety. The running rigging is used to hoist and/or control the sails. Halyards are used to hoist the sails into position; sheets are attached to the sails and are used primarily to control the angle of the sails to the boat's centreline, and therefore the wind. The running rigging will also generally include ropes that are used to control the position of moveable components of the boat, which are used for fine adjustment of the sails.

Many different methods have evolved that allow one rope to be attached to another, to a fixed point or to a sail. One common method is to create an eye with a knot, or a splice, or by binding or stitching the end of the rope to the standing part with twine. This last method is called seizing. A knot is defined as 'a way of 
joining or securing lengths of rope, thread, or other strands by tying the material together or around itself'. A splice is defined as a way 'to join ends of ropes by intertwining strands'. Unlike knots, a specific splice is suitable only for a specific type of rope.

The ropes used in sailing are similar in appearance to those utilised by climbers, but the materials used are different. Climbing ropes are designed to absorb shock loads in the event of a fall, and are of relatively low stiffness. By contrast, sailing ropes need to have high stiffness to preserve precise control by minimising elastic extension. Whereas it is generally accepted that climbing ropes do not fail, either at a knot, or generally, unless loaded over an edge (Schubert, 2002; Bailie, 2000), sailing ropes are subject to failure, particularly near the ends where high degrees of wear and chafe are possible during extended use. In addition, sailing ropes are subjected to high static loadings, upon which considerable dynamic fluctuations are superimposed. These ropes are also prone to ultra violet attack due to prolonged exposure in the marine environment.

A wealth of information has been published concerning the suitability of the various methods of forming a loop termination. This information is available in books specifically dedicated to knots and splices, e.g. Jarman (2000), Shaw (2004), and Pawson (2001). It may also be found in standard sailing textbooks (Cunliffe, 2000). Recent articles in the sailing press demonstrate the continuous development of ropes and splicing techniques (James, 2003; Pawson, 2005).

The published research on polymeric ropes is somewhat limited. Manes (2002) has reviewed work carried out on the structure of ropes for rock climbing. Leech (2002) considers the hierarchical structure built up from individual strands, bundles, and sub-ropes, to make the overall cable. He also considers the frictional load transfer between the elements of the rope. Pan \& Brookstein (2002) have reviewed the recent work that has been carried out on the modelling of polymer ropes.

The theory of knots has stimulated some interest in the mathematics community. This is typified by the Fields Medal winning work of Vaughan Jones, as reviewed by King (1986). At a fundamental level, the effect of a knot on the strength of a single polymer strand is discussed by Saitta et al. (1999). This is more of interest to the polymer scientist due to the microscopic scale of the fibres in question. Wu (1993) considered friction and slippage between the strands of polymeric ropes, and made some observations concerning slippage in end terminations.

A particular method for forming an eye termination might be selected because it is easy to form or release, because it holds securely, because it is compact and will slide over apparatus easily, or because it is considered relatively strong. The presence of the eye termination can have a significant effect upon the fatigue life of a line, its response under dynamic loading and its static breaking load. While much experimental and analytical work has been conducted upon synthetic ropes, knowledge about eye terminations is limited. Advice on how to create eye terminations is generally based upon one-off tests or tradition. There is no definitive guide about which knot to choose or how to form a splice in order to get the highest splice efficiency, which is defined as the ratio of the breaking strength with the eye to the rope strength.

Limited mathematical modelling has been carried out. Maddocks \& Keller (1987) propound the mechanics of some simple hitches while Leech (2003) models the stresses in some commonly used splices. However, such models are founded upon numerous assumptions and, although they help to understand the mechanics involved, they do not provide accurate predictions of the breaking loads or the effect of changing one of the huge number of variables, such as the maker of the eye (referred to hereafter as the manufacturer), rope type, eye size, length of the working end or the type of loading. This project has attempted to carry out an assessment of the static strength of knots and splices used in a sailing environment and the factors that affect this strength.

The aim of this study was to carry out a comprehensive preliminary assessment of the static breaking strength of several common eye terminations. These included four knots - the bowline, double bowline, perfection loop and figure-of-eight loop - and two splices - the three-strand eye splice and the braid-onbraid splice. The effect of various factors upon the breaking strength of the line was investigated and the practical relevance of the results discussed. 


\section{Experimental procedure}

This section describes the programme of experimental work. First, the determination of the initial baseline strength of each rope type and diameter is described. Secondly, the preparation of knots and the method by which eye splices were prepared, using the specific method appropriate to each rope type, is discussed. Thirdly, the apparatus used to test the loops is detailed. Finally, the procedure used to test the strength of the knots and splices, and the means by which data were recorded, is reviewed.

\section{Determination of rope strength}

Two different commercially available types of rope were used to make the knots and splices. Both rope types were manufactured by Liros Ropes Ltd (Germany). The first was a 16-plait braid-on-braid polyester rope, sold as the LIROS Top Cruising rope. The second was a three-strand twisted pre-stretched polyester rope, sold as the LIROS Prestretch rope. In the course of the project, ropes of 6,8 and $12 \mathrm{~mm}$ diameter were used.

The breaking loads of all diameters of three-strand rope were found. Only the breaking load of the $8 \mathrm{~mm}$ braid-on-braid rope was found, due to the limitations of the project. The rated breaking load was taken for the 6 and $12 \mathrm{~mm}$ braid-on-braid ropes. The testing was carried out by Marlow Ropes (now part of Bridon International Ltd) on an AJT horizontal tensile test machine, as specified in BS EN 919 (1995). For each sample set, three samples were tested and the mean static break load was calculated. The results are shown in Table 1.

\section{Sample preparation}

The knots were made using both types of $8 \mathrm{~mm}$ rope. Splices are specific to the type of rope construction. A

Table 1 Average breaking load for the four types of rope tested by Marlow Ropes (now part of Bridon International Ltd)

\begin{tabular}{lcc} 
Type of rope & Diameter $(\mathbf{m m})$ & Average break load $(\mathbf{k N})$ \\
\hline 3-strand & 6 & 9.22 \\
3-strand & 8 & 12.56 \\
3-strand & 12 & 29.23 \\
Braid-on-braid & 8 & 14.42 \\
\hline
\end{tabular}

three-strand eye splice was manufactured from the pre-stretched rope while a braid-on-braid splice was manufactured from the braid-on-braid rope. The eye size was defined as the inside length of the eye, measured with a flexible tape. The working end is the unloaded end of the rope.

All knot and splice samples were finished in the same manner. A mark was made $1.3 \mathrm{~m}$ along the standing part of the rope, measuring from the crotch of the eye. The rope was whipped either side of the mark, cut and the end sealed by melting.

\section{Knots}

The four knots investigated were the bowline, double bowline, figure-of-eight loop and perfection loop, shown in Fig. 1. Each sample was prepared with a $100 \mathrm{~mm}$ working end and a $150 \mathrm{~mm}$ internal eye size.

\section{Three-strand eye splice}

The eye splices were manufactured as shown in Fig. 2. Jarman (2000) gives a step-by-step guide of how to do this. The standard eye splice had four tucks and a $15 \mathrm{~cm}$ internal eye size. It was manufactured from an $8 \mathrm{~mm}$ diameter rope by the author. Once the splice was completed the working ends were cut to a length of about $5 \mathrm{~mm}$. The splice was rolled under foot three times to settle it.

The following factors were varied during the study, to find their effect on spice efficiency:

- number of tucks

- manufacturer

- eye size

- rope diameter.

The factors were varied one at a time to allow direct comparison of the results. This method did not, however, allow interdependency of the factors to be studied.

Splices with two, three, four and eight tucks were tested. Samples were prepared by three different manufacturers: two adult males and one adult female, all of whom had little previous experience of making splices. The different eye sizes tested were 8,15 and $25 \mathrm{~cm}$. $8 \mathrm{~cm}$ was the smallest eye that could pass over the shackle used in the test rig. Rope diameters of 6,8 and $12 \mathrm{~mm}$ were tested. 

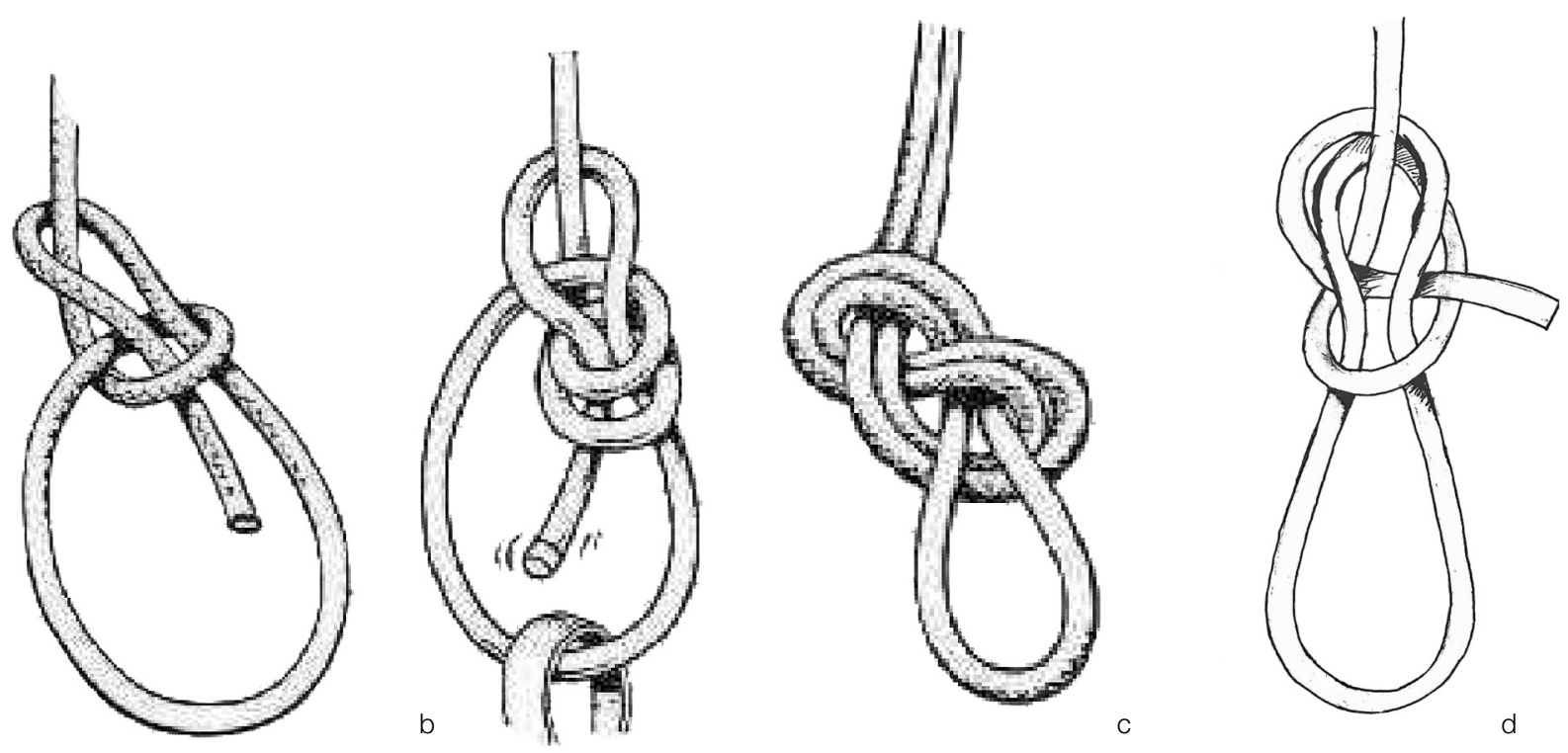

Figure 1 Knots investigated in the current work: a) bowline, b) double bowline, c) figure-of-eight loop, d) perfection loop.
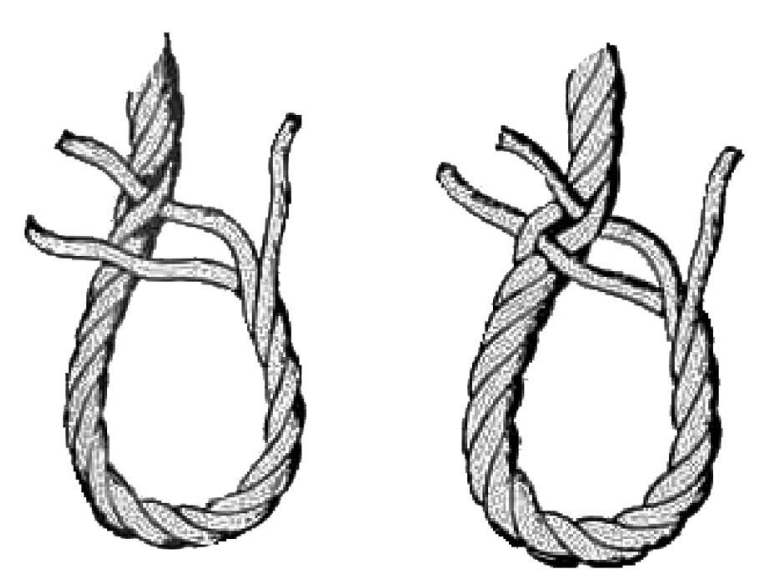

Figure 2 Sequence of operations involved in the manufacture of an eye splice in three-strand prestretched rope. After Jarman (2000).

\section{Braid-on-braid eye splice}

The braid-on-braid splices were manufactured as shown in Fig. 3. Again the reader is referred to Jarman (2000) for detailed instructions.

The factors considered for this splice were:

- splice length

- eye size

- rope diameter.
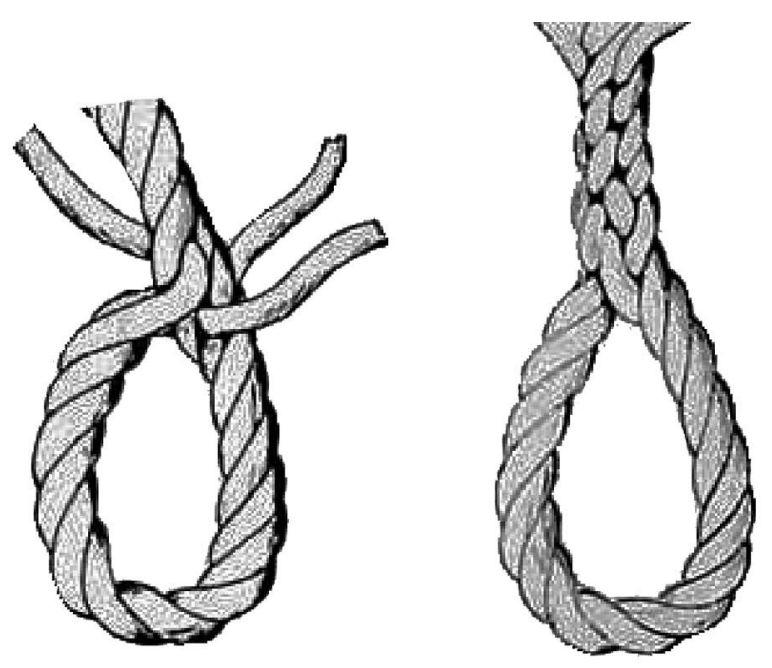

Again eye sizes of 8,15 and $25 \mathrm{~cm}$ and rope diameters of 6,8 and $12 \mathrm{~mm}$ were tested. Variation of the splice length for a braid-on-braid splice was more difficult. Unlike the three-strand eye splice, the internal construction of the braid-on-braid splice, shown in Fig. 4, has an infinite number of possible variations. Dimension OA dictates the final length of the splice. Dimension DE dictates the length for which the sheath passes through the core. Dimension 
$\mathrm{CD}$ is critical in the construction of the splice, as it dictates the amount of sheath that is pushed back. If it is too short it becomes very difficult to milk the sheath over the splice from $\mathrm{O}$ to A. Dimension CD could, therefore have an effect upon the breaking strength of the rope. If it is very short the sheath has to be strained excessively to make it pass over the splice. This process involves a lot of abrasion.

Initially, just two samples were tested for each variation in splice length. Where differences in breaking load were significant the sample sets were extended. Seven different splice constructions were tested. These are labelled as Types I to VII. Type I is the standard as described in Jarman (2000). Type II varied the relative length of $\mathrm{CD}$ to OA. Type III varied the absolute length of the splice. Types IV to VII varied the amount of core overlap in the internal construction. The variations are summarised in Table 2 and Fig. 5. 'Fid' implies the length of one Swedish fid (the hollow tool shown in Fig. 3), which is approximately $14 \mathrm{~cm}$. For accuracy the length was measured with a tape measure.
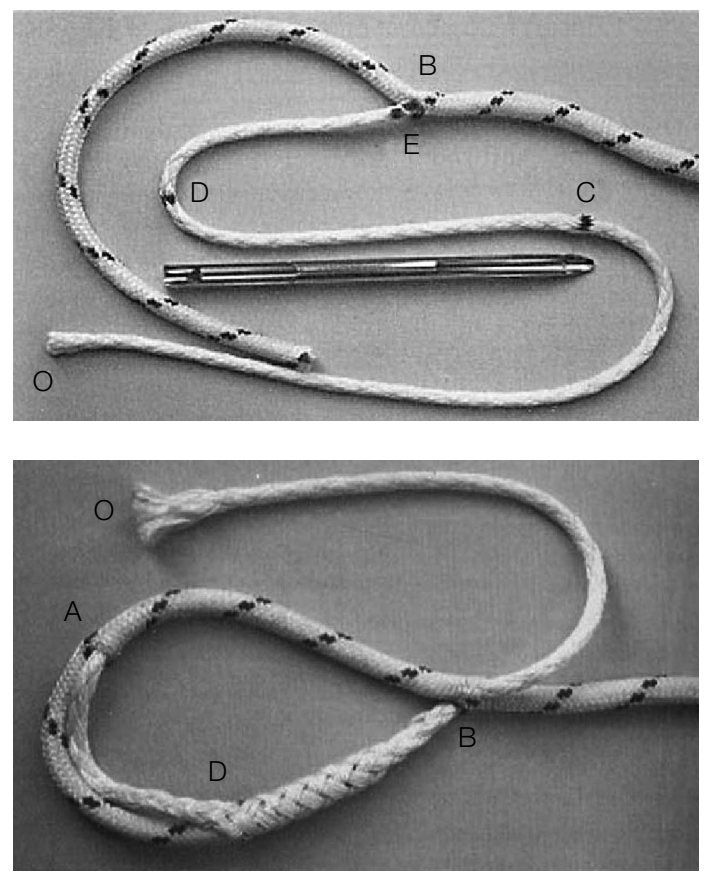

Figure 3 Sequence of operations involved in the manufacture of a braid-on-braid splice. The 'fid', referred to in the text, and in Table 2, is the metal needle, approximately $14 \mathrm{~cm}$ in length shown in the Figure. After Jarman (2000).

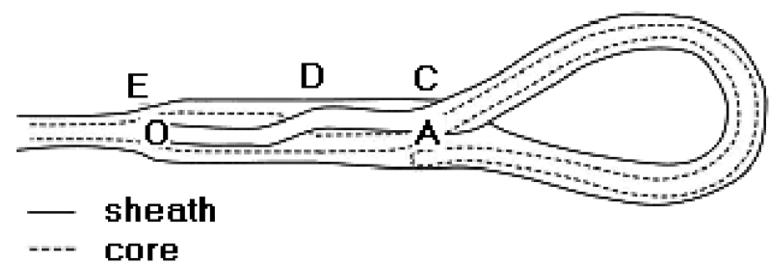

Figure 4 Internal construction of the braid-on-braid splice, showing significant points in the structure. The distances between these points define the geometry of the splice in Table 2.
Table 2 Splice constructions for braid-on-braid splices. Here, the geometry is characterised by the lengths of rope between the significant points labelled in Figs. 3 and 4. 'Fid' refers to the length of a Swedish fid, the $14 \mathrm{~cm}$ long splicing needle shown in Fig. 2

\begin{tabular}{llll} 
Splice length & OA & DE & CD \\
\hline Type I & $1 \mathrm{fid}$ & $2 / 3 \mathrm{fid}$ & $1 \mathrm{fid}$ \\
Type II & $1 \mathrm{fid}$ & $1 / 3 \mathrm{fid}$ & $1 \mathrm{fid}$ \\
Type III & $1 / 2 \mathrm{fid}$ & $1 / 3 \mathrm{fid}$ & $1 / 2 \mathrm{fid}$ \\
Type IV & See Fig. 5 & & \\
Type V & See Fig. 5 & & \\
Type VI & See Fig. 5 & & \\
Type VII & See Fig. 5 & & \\
\hline
\end{tabular}



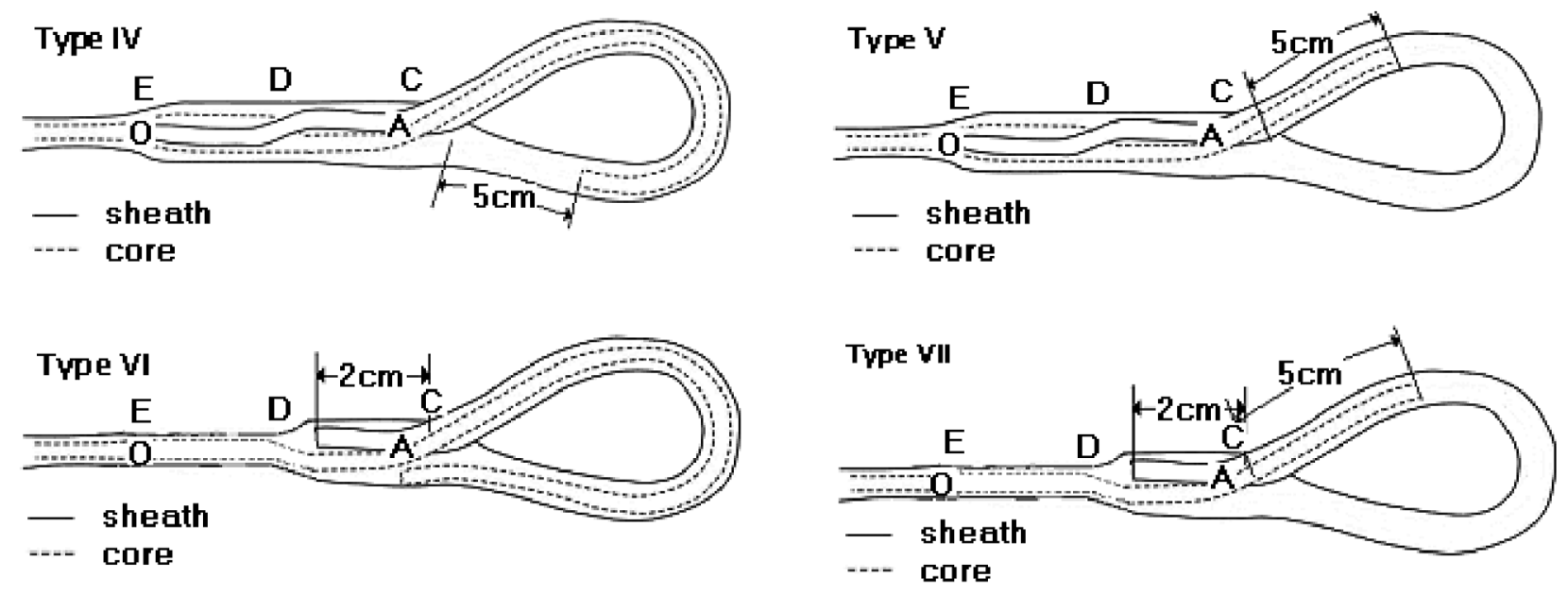

Figure 5 Internal construction of Type IV to VII splices, showing significant points in the structure.

The distances between these points define the geometry of the splice in Table 2.

\section{Test apparatus}

Three rope manufacturers were contacted to determine the method by which eye splice strengths are currently measured. The companies concerned were:

- New England Ropes, Fall River, MA, USA (T. DaCosta)

- Liros Ropes, Lichtenberg, Germany Rosenberger)

- Marlow Ropes, Hailsham, UK (T. Scofield) (now part of Bridon International Ltd)

The current method for testing eye terminations in industry involves creating a line with an eye in each end. The eyes are then looped over pins in a tensile testing machine and the line is loaded at a constant crosshead velocity until failure occurs. The line will always fail at its weakest point (Pan, 1996), which, if the rope has been manufactured correctly, should lie at one of the eye terminations. The major limitation of this test method is that the breaking load of the weaker eye is invariably measured. Statistically, then, a set of data obtained from this test will be inherently flawed.

The method adopted for this work, an adaptation of the support used to drop test dynamic mountaineering ropes, BS EN 892 (1996), allowed each individual eye termination to be tested. The eye termination was looped over a shackle that was attached

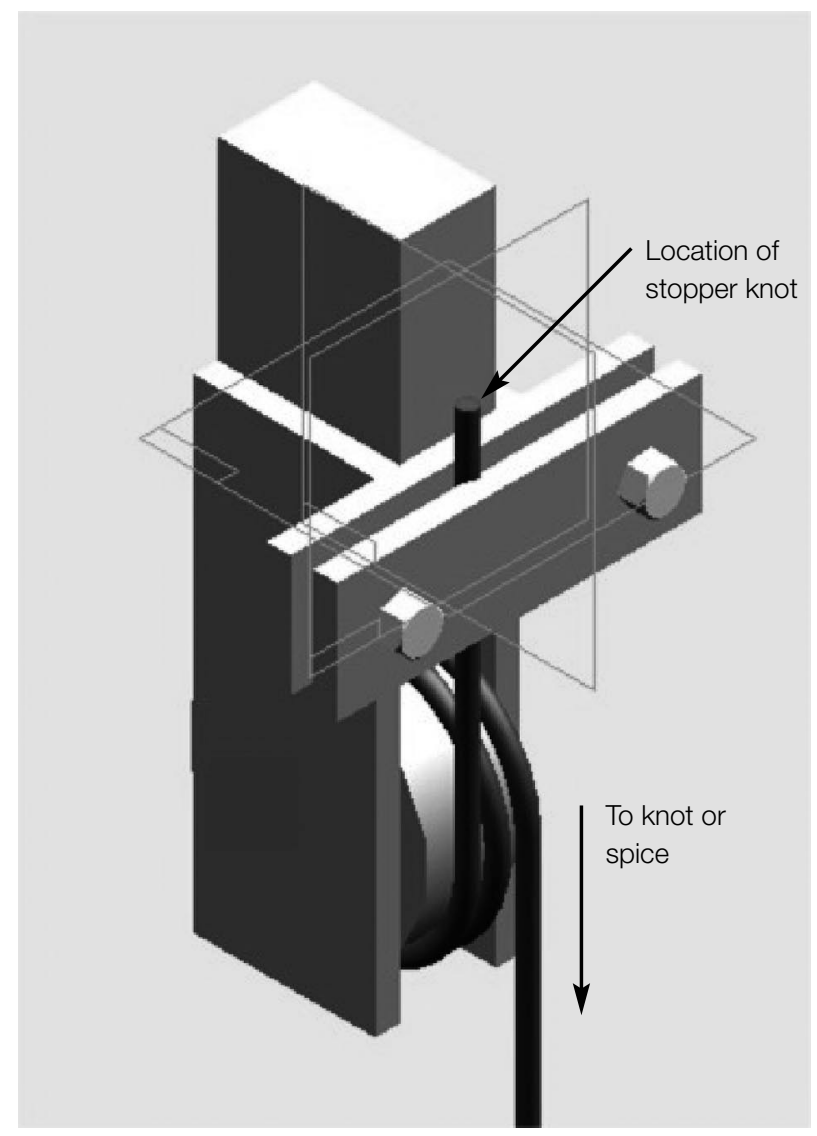

Figure 6 Upper support. Utilised in the present work for the attachment of the standing part of the rope to the tensile testing machine. The position of the stopper knot and eye are indicated. 
to the moving crosshead of a tensile testing machine. As illustrated in Fig. 6, the standing part of the rope was wrapped around a $100 \mathrm{~mm}$ diameter drum, passed through a clamp and then a stopper knot was tied in the end. The stopper knot prevented the rope from slipping through the clamp under tension. The upper and lower supports were carefully designed such that neither presented a greater weakness in the rope than the eye termination itself; there were no sharp edges and the rope did not follow any tight bends over the supports. Furthermore, to prevent failure at the stopper knot, the rope was wrapped at least twice around the drum, thereby reducing the tension in the rope at the clamp. A test was considered valid when the rope broke at the eye termination.

The disadvantage of this method was that, as the rope could not be totally constrained at the drum, it did not allow accurate measurement of the elongation. The measured value of elongation included the strain for the entire length of rope, from the eye termination to the clamp, and any slack that had existed in the setup. Bedding-in (loading of the sample prior to the main run to a value well below its breaking strength) was used to take up the slack and thereby limit the extent of this problem.

\section{Sample testing}

The samples were tested in a Tinius Olsen 81000 vertical tensile testing machine with a load capacity of $200000 \mathrm{lb}(4325 \mathrm{kN})$ and a maximum stroke of $2 \mathrm{~m}$, in order to find their breaking load. A mark was made on each sample $300 \mathrm{~mm}$ from the crotch of the eye. The standing part of the sample was wrapped twice around the drum and the mark was aligned with its horizontal longitudinal axis. The standing part was then passed through the clamp and a stopper knot was tied in the end. The upper support was clamped into position in the tensile testing machine. The eye termination was threaded through a shackle attached to the moving crosshead.

The samples were bedded-in by increasing the load to $10 \%$ of the rope's rated breaking load three times (except for Type VII braid-on-braid splices, where the failure load was too unpredictable). Each sample was then loaded until failure by applying a constant crosshead speed of $1 \mathrm{~mm} / \mathrm{s}$. The experiment was repeated at least five times for each sample set.
The breaking load was defined as the highest load reached in the rope prior to complete failure. In a reallife situation the load would not be relaxed after the initial failure and, having reached the maximum supported load, catastrophic failure would follow. For the three-strand pre-stretched rope the maximum supported load was attained just before the first strand broke. After this initial failure, relaxation of the twisted structure occurred, and the load in the line reduced significantly. The other two strands would subsequently break at much lower loads. In comparison, in the braid-on-braid splices, the core of the rope failed first. The sheath finally failed at an even higher load.

An analogue plotter, a dial gauge and a computer program, which took measurements at 3 second intervals, logged the breaking load and elongation. The data obtained from the computer is given here. These measurements were the most precise (to the nearest $0.01 \mathrm{lb}$ or $0.22 \mathrm{~N}$ ), but data was captured only once every three seconds, meaning that the maximum breaking load recorded was marginally lower than the actual maximum breaking load. All values were verified against those obtained from the analogue plotter and the dial gauge.

\section{Results and analysis}

This section presents an analysis of the results of the tests carried out. First, a description of the statistical techniques utilised is presented. Secondly, a comparison between the strengths of the four knots is discussed. Next, the factors that affect the strength of three-strand eye splices are analysed. Finally, the variation in strength of braid-on-braid eye splices is described.

\section{Statistical analysis}

The inherent variance in the breaking strength of ropes is significant. Ropes are discontinuous structures manufactured by the twisting or braiding of yarns of fibre. The tensile strength of a given length of rope is dependent upon many factors, including the chemistry of the fibres, the manufacturing method, the number of slack and damaged fibres present from manufacture (Phoenix, 1979), and the type of rope construction. Further variability is introduced by human error when an eye termination is made in a rope. There are also errors in the testing technique. 
These factors are difficult to control. The consequence is that no two samples will be exactly the same and there will be random variance in the measured breaking loads. One alternative is to try to control these factors. However, within the limits of this project, this was impracticable. Further, on the basis that such errors would exist in any eye termination created in the real world, it was decided that it was in fact essential to include these variations so that the real significance of any results could be demonstrated. However, drawing conclusions from data sets with such a degree of variance can become very difficult. A statistical approach was therefore adopted.

The sample mean and so the average knot or splice efficiency were calculated for each sample set. Only the efficiency is quoted here. Knot efficiency is defined as:

$$
\text { knot efficiency }=\frac{\text { line strength with } \text { knot }}{\text { line strength }}
$$

The sample standard deviation was also calculated in order to find the estimated standard error (ESE) of the data. The ESE indicates how representative the sample mean is of the population mean. The highest ESE for any sample set was calculated as $45.1 \%$ of the average breaking load; however this was for a particularly unpredictable sample set. The next highest ESE was $5.44 \%-$ most of the errors were around $3 \%$. It was concluded that the sample mean was a sufficiently accurate point estimate of the population mean.

The effect of varying a factor was initially analysed by comparing the means and spreads of sample data. Even though trends appeared, it was difficult to state objectively whether the factor had an effect due to the degree of variance in the results. A one-way analysis of variance (ANOVA) was carried out in these cases to allow an objective decision to be made.

Montgomery et al. (2001) give a detailed explanation of ANOVA and hypothesis testing. The null hypothesis posed was that changing the factor had no effect. Using a statistics programme the $P$-value $\left(0 " P^{\prime \prime} 1\right)$ for the sample set was calculated. In general, if the $P$-value is small then the evidence against the null hypothesis is very strong. It can be concluded that the factor in question does affect the breaking load of the rope. If the $P$-value is large then the evidence for the null hypothesis is strong. It can be concluded that the factor does not affect the breaking load of the rope.
ANOVA assumes that the population distribution is normal, that the observations are independent and that, except for variance caused by the factor, variance is the same at each treatment level (each level of variation of the factor). These assumptions were verified by examining plots of the residuals. The analysis was carried out using the MINITAB computer programme.

\section{Knots}

The standing part of the rope, as it exits an eye, will carry the entire load. The working or free end will carry no load. The load is transferred from the standing part to the working part through the knot or splice until the load is shared equally at the crotch. Load transference occurs through friction and contact between the different parts of the rope. In a knot, because of the complex geometry, the load decreases suddenly where parts of the rope come into contact (Maddocks and Keller, 1987).

The mechanisms of failure in an eye are extremely complex. In any length of rope the shortest fibres will initially take the entire load and fail first. The load will then redistribute and can be increased further until the longer fibres start to fail. Failure occurs catastrophically when a certain number of fibres have failed. In an eye the fibres fail due to stress created by contact, friction or bending, or by abrasion. Abrasion occurs as the knot tightens: fibres both slide over one another and move across one another at an angle, in a cutting action (Leech, 2003).

The position of failure of the knots was observed, with the aid of a high-speed camera. Both the figureof-eight loop and the perfection loop failed just where the standing part enters the body of the knot, as shown in Fig. 7. The position of failure of the bowline and double bowline was not clear. It appeared to fail at the first bend after the standing part enters the knot. However, failure occasionally occurred in other positions. Failure where the standing part enters the knot makes sense: the entire standing part of the rope will see the entire load but, at the point of entry, stresses due to contact and friction are superimposed.

As shown in Table 3, the general trend in the breaking load was the same for both the three-strand and the braid-on-braid rope; the figure-of-eight loop 

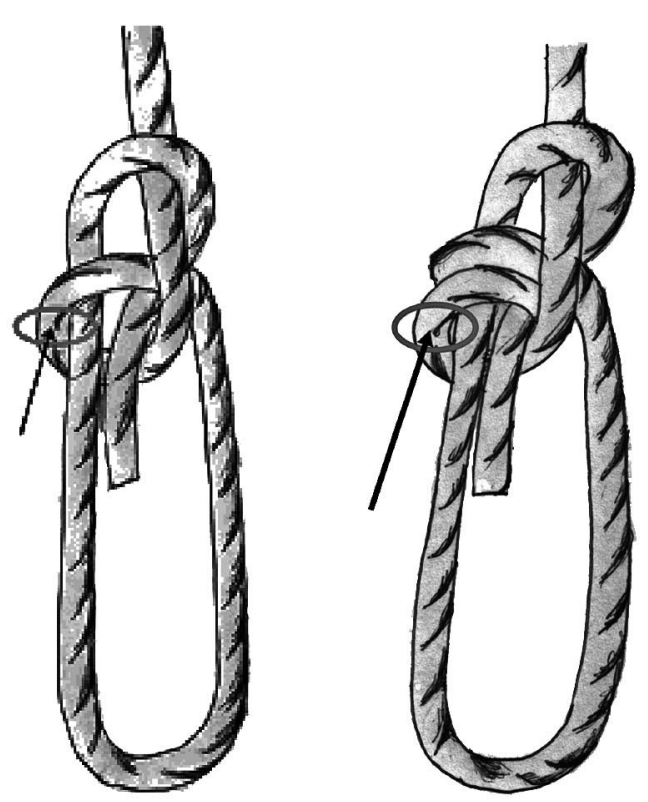

Figure 7 The ellipses indicate the observed positions of failure of the four knots. These are, from left to right: bowline, double bowline, figure-of-eight loop, perfection loop.

was the strongest by a significant margin, the perfection loop the weakest and there was little difference between the bowline and the double bowline. Analyses of variance were carried out to see if changing the knot had any significant effect upon the breaking load. The difference between the bowline and the double bowline was found to be statistically insignificant with a $P$-value of 0.346 for knots made in three-strand rope and a $P$-value of 0.365 for braid-on-braid rope; the knots are practically interchangeable.

In general, then, it was the knots with tighter bends and more numerous crossovers that proved to be the weakest. The figure-of-eight loop is considerably stronger than the others. Sailors generally attach sheets

Table 3 Results of breaking strength tests on knots formed in the three-strand prestretched and braid-on-braid rope. In each case, knot efficiency is defined as breaking strength of the knot / breaking strength of the rope alone.

\begin{tabular}{lcc} 
Knot type & $\begin{array}{c}\text { Three-strand rope } \\
\text { Knot efficiency }\end{array}$ & $\begin{array}{c}\text { Braid-on-braid } \\
\text { Knot efficiency }\end{array}$ \\
\hline Bowline & 0.66 & 0.62 \\
Double bowline & 0.63 & 0.64 \\
Perfection loop & 0.60 & 0.55 \\
Figure-of-eight loop & 0.76 & 0.84 \\
\hline
\end{tabular}
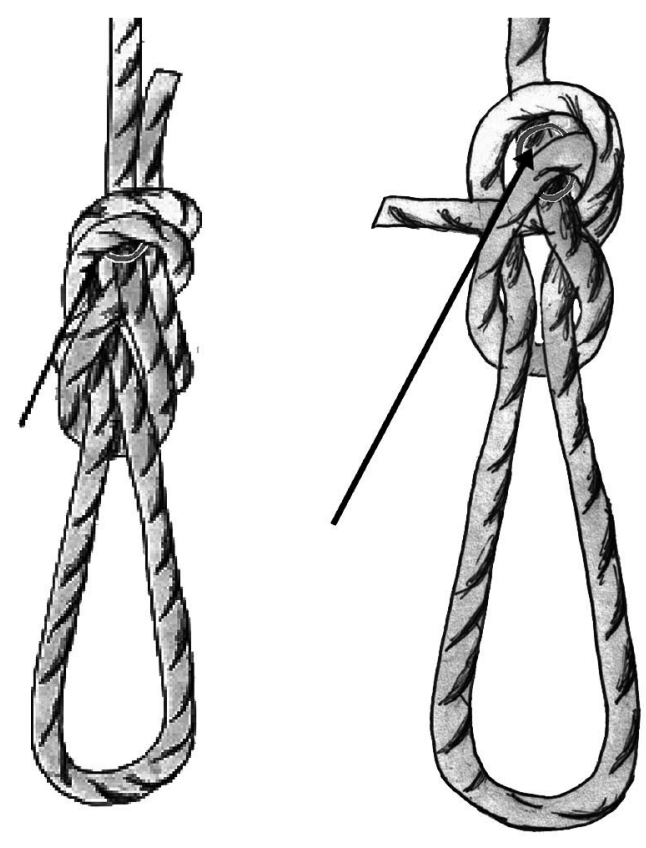

to the clew of sails by using a single bowline, as it is easy to tie and untie quickly. During sail changes speed is important; so strength and security are sacrificed. In rock climbing circles, the figure-of-eight loop is the knot of choice for climbers when they attach the rope end to their harness. In this case, they clearly value security and strength above all other considerations.

\section{Three-strand eye splice}

In a splice, unlike a knot, the load transference will occur continuously along its length. For both of the splices observed, failure occurred at the very end of the splice. Many of the splices had efficiencies greater than 1, suggesting that the presence of the splice increases the strength of the rope. However, it was concluded that this could not be the case as the rope invariably failed at the splice rather than at any other point. Splice efficiencies greater than 1 must be anomalous. The rope used to determine the rope strength was purchased almost a year after the bulk of the knot and splice testing was carried out. The low rope strength may simply be a result of the variance in rope strength between different batches. If the study were to be repeated, the rope strength of the original batch would be tested at the outset. 


\section{Variation of the number of tucks}

The splices with three, four or eight tucks failed by breaking. The splices with only two tucks failed by slipping. This observation was reflected in the calculated splice efficiencies, listed in Table 4. The longer splices all had extremely high efficiencies with very little variance between them, whereas a two-tuck splice could support only $73 \%$ of the rope's rated breaking strength. This is only comparable to the strength of the stronger knots. It is a measure of the relative security afforded by splicing as compared to knots that even two-tuck splices are of similar strength to the best knot tested. However, again it is noted that a knot is often preferred for ease of tying and untying.

Failure by slipping probably occurs due to dilation of the rope during loading. Most continuous materials exhibit a Poisson's ratio effect when loaded. In ropes, the fibres not only contract radially but they move together, changing the shape of the strands, to use up the least possible space. If this effect is not complemented by an increase in the resisting frictional forces then the splice can simply unravel. The fact that this occurs below a certain number of tucks implies the existence of a critical splice length.

It was hypothesised that above this critical splice length an increase in the number of tucks had no effect upon the breaking load. An analysis of variance was carried out on the splice data for three, four and eight tucks. The resulting $P$-value was 0.693 , supporting the hypothesis. This seems logical. The splices that fail by breaking do so at the top of the splice. At this point the rope strands are carrying the full line tension; very little load transference to the splice strands has occurred. Furthermore, the presence of the splice strands distorts the rope geometry so that the tension in the strands at this point is greater than that in the undisturbed line above the splice (Leech, 2003). The loads developed at

Table 4 Effect of variation of number of tucks on the splice efficiency of three-strand prestretched ropes.

\begin{tabular}{lll} 
Number of tucks & $\begin{array}{l}\text { Splice efficiency } \\
\text { (computer) }\end{array}$ & $\begin{array}{l}\text { Splice efficiency } \\
\text { (analogue plotter) }\end{array}$ \\
\hline 2 & 0.73 & 0.74 \\
3 & 1.07 & 1.09 \\
4 & 1.08 & 1.10 \\
8 & 1.10 & 1.12 \\
\hline
\end{tabular}

the point of failure would therefore depend upon the geometry rather than the splice length.

\section{Variation of the manufacturer}

The results for variation of the manufacturer, i.e. the person making the splice, are presented in Table 5 . An analysis of variance was carried out which showed that the breaking loads are independent of the splice manufacturer $(P=0.641)$. It is noted that all the manufacturers had little experience of splicing, and therefore it is suggested that further testing be carried out, perhaps involving professionals. It is thought unlikely however that a professional's splice would be stronger than that of an amateur, so long as the splice geometry was correctly formed in both cases. This is significant since it indicates that any reasonably competent person can make three-strand splices that achieve the maximum possible strength.

\section{Variation of the eye size}

The results for variation of the eye size are presented in Table 6. A trend was apparent; an increase in eye size appeared to cause a slight decrease in splice efficiency. ANOVA of the data did not strongly support the existence of a trend. The P-value was 0.277 . There is therefore a possibility that breaking load varies with eye size but not substantially. More extensive testing at more treatment levels would need to be carried out before a strong conclusion could be made. It is not obvious why the eye size would affect the splice efficiency as the angle of entry of the first tuck does not affect the geometry of the developed splice.

\section{Variation of the rope diameter}

Variation of the rope diameter gave unexpected results. These are summarised in Table 7. The $8 \mathrm{~mm}, 4$ tuck

Table 5 Effect of variation of manufacturer (the individual making the splice) on the splice efficiency of three-strand prestretched ropes.

\begin{tabular}{lll} 
Manufacturer & $\begin{array}{l}\text { Splice efficiency } \\
\text { (computer) }\end{array}$ & $\begin{array}{l}\text { Splice efficiency } \\
\text { (analogue plotter) }\end{array}$ \\
\hline Female 1 & 1.08 & 1.10 \\
Male 1 & 1.06 & 1.08 \\
Male 2 & 1.06 & 1.07 \\
\hline
\end{tabular}


Table 6 Effect of variation of eye size on the strength of splices in prestretched three-strand ropes.

\begin{tabular}{lll} 
Eye size, cm & $\begin{array}{l}\text { Splice efficiency } \\
\text { (computer) }\end{array}$ & $\begin{array}{l}\text { Splice efficiency } \\
\text { (analogue plotter) }\end{array}$ \\
\hline 8 & 1.11 & 1.13 \\
15 & 1.08 & 1.10 \\
25 & 1.05 & 1.07 \\
\hline
\end{tabular}

splice had an efficiency of $104 \%$, but 4 tuck splices made from the $6 \mathrm{~mm}$ and $12 \mathrm{~mm}$ ropes were both considerably weaker, with splice efficiencies of $63 \%$ and $83 \%$ respectively. It was expected that if the splice geometries (the pitch, ratio of fibre diameter to rope diameter, and number of fibres per strand) for different diameters of rope were identical then the splice efficiency would be the same. However, as this was not the case and the same diameter fibres are used to manufacture all diameters of rope, it was expected that the rope diameter might have an effect upon the breaking load. However, there is no obvious trend in these results.

The packing ratio of a rope is defined as the ratio of the rope density to the material density (Leech (1987)). It was assumed that the material density was constant. The rope densities per unit length were calculated for the 6,8 and $12 \mathrm{~mm}$ diameter ropes and are listed in Table 7, alongside the splice efficiencies. An increase in packing ratio corresponds to an increase in splice efficiency. This is in agreement with the results predicted by Leech (2003) for the Admiralty splice. However, the effect here is far more pronounced. More extensive testing would be required to fully understand the effect and interdependency of various factors.

\section{Braid-on-braid splice}

\section{Variation of splice length}

The results of changing the splice length are reported in Table 8. As with the three-strand splices, two different failure modes were observed. Types I to $\mathrm{V}$ (Fig. 4 and Fig. 5) failed by breaking at the top of the splice. At this point the load in the rope is highest and amplified by the disturbance in the rope geometry. The ANOVA for Types I to V give a P-value of 0.365 , suggesting that the variation of the splice construction has no effect on the breaking load.

An ANOVA for Types I and II splices alone was carried out, giving a P-value of 0.147 . This suggests
Table 7 Effect of variation of rope diameter on the strength of splices in three-strand prestretched ropes. Rope densities per unit length for each diameter are also shown.

\begin{tabular}{llll}
$\begin{array}{l}\text { Rope diameter, } \\
\mathrm{mm}\end{array}$ & $\begin{array}{l}\text { Splice efficiency } \\
\text { (computer) }\end{array}$ & $\begin{array}{l}\text { Splice efficiency } \\
\text { (analogue plotter) }\end{array}$ & $\begin{array}{l}\text { Rope density per } \\
\text { unit length }\left(\mathrm{kg} / \mathrm{m}^{2}\right)\end{array}$ \\
\hline 6 & 0.63 & 0.65 & 1138.82 \\
8 & 1.04 & 1.10 & 1263.28 \\
12 & 0.83 & 0.84 & 1149.45 \\
\hline
\end{tabular}

Table 8 Effect of variation of splice length on the efficiency of braid-on-braid splices.

\begin{tabular}{lll} 
Splice length & $\begin{array}{l}\text { Splice efficiency } \\
\text { (computer) }\end{array}$ & $\begin{array}{l}\text { Splice efficiency } \\
\text { (analogue plotter) }\end{array}$ \\
\hline Type I & 0.98 & 0.98 \\
Type II & 1.03 & 1.04 \\
Type III & 1.00 & 1.02 \\
Type IV & 0.97 & 1.01 \\
Type V & 0.99 & 1.00 \\
Type VI & 0.82 & 0.84 \\
Type VII & 0.15 & 0.24 \\
\hline
\end{tabular}

that changing length CD may affect the splice efficiency, as discussed in the sample preparation section, but testing of more samples at more lengths of CD would be required.

One of the five Type VI samples failed by slipping, one failed by breaking and the remaining three failed by a combination of slipping and breaking. In the latter case, the core failed at point A, shown in Fig. 4, and the sheath slipped out. Despite the different failure modes the failure load was consistent; the mean splice efficiency was $82 \%$, compared to around $100 \%$ for Types I to $\mathrm{V}$ splices, with an estimated standard error of $4.58 \%$.

All Type VII samples failed by slipping at considerably lower loads. Interestingly, the variance in failure load for these samples was large; the estimated standard error as a percentage of the mean rope breaking load was $45 \%$.

Only the splices with the shortest internal overlap failed by slipping. It is obvious then that the overlap is essential for both maintaining the geometry of the splice and developing friction that resists slippage upon loading. The length $\mathrm{OA}$ appears to be more critical in preventing slippage; reducing the length of core threaded through the eye, as was done for Type IV and V splices, has little effect on its own. A combination of a short OA and a short overlap in the eye, as 
with Type VII splices, invariably results in failure through slipping at very unpredictable loads.

In general then, the braid-on-braid splice behaves similarly to the three-strand splice. Above a certain splice length the sample fails by breaking and the breaking load is independent of the construction. Below a certain splice length the sample fails by slipping. In this case the failure load is more unpredictable than for the three-strand rope, possibly because of the more continuous nature of the splice.

Variation of eye size

The results of variation of eye size are shown in Table 9. The ANOVA carried out on the data for variation of the eye size gave strong evidence to support the null hypothesis, i.e. it has no effect upon breaking load. This splice geometry is radically different from that for the three-strand rope. The eye size in this case almost certainly has no effect upon the load state at the point of failure.

\section{Variation of rope diameter}

The results for varying the rope diameter, shown in Table 10, are almost identical to those for the threestrand splice. The $8 \mathrm{~mm}$ Type I splice gave an efficiency of $98 \%$. Splices in the $6 \mathrm{~mm}$ and $12 \mathrm{~mm}$ rope gave efficiencies of $63 \%$ and $75 \%$ respectively. These results raise the same issues noted previously. The fact that the trends for both rope types are the same is curious, especially as the two splice geometries are so dissimilar.

Again the rope densities per unit length were calculated for the 6,8 and $12 \mathrm{~mm}$ diameter ropes and are listed in Table 10, alongside the splice efficiencies. The highest splice efficiency corresponds to the highest rope density but that is where the correlation ends. Again, more testing would be required to understand the interdependency of the factors.

Table 9 Effect of variation of eye size on the efficiency of braid-onbraid splices.

\begin{tabular}{lll} 
Eye size, $\mathrm{cm}$ & $\begin{array}{l}\text { Splice efficiency } \\
\text { (computer) }\end{array}$ & $\begin{array}{l}\text { Splice efficiency } \\
\text { (analogue plotter) }\end{array}$ \\
\hline 6 & 0.98 & 1.00 \\
8 & 0.98 & 0.98 \\
12 & 1.00 & 1.01 \\
\hline
\end{tabular}

\section{Conclusions}

When considering methods of making eye terminations for a sailing environment, it is very unlikely that an improvement of a few percent in the breaking load will be sufficient to encourage the adoption of different manufacturing practices. This is particularly true when general variance due to the rope itself can far outweigh such a small gain. It is therefore inadvisable to spend excessive amounts of time determining whether the eye size, for example, definitely affects the average breaking load of a three-strand eye splice, especially when the eye size is to a large extent dictated by the purpose of the eye termination anyway.

From this point of view the most interesting results of the investigation have been:

- The demonstration that there is no difference in strength between the single and double bowline, despite traditional opinion.

- The difference in breaking load between knots. If strength alone were considered the figure of eight knot would be the obvious choice (this and its security make it a common preference in climbing). However, other issues such as the length of rope required and the ease of tying and untying means that the bowline may be preferred. The perfection loop is not recommended; it is weak, complex to tie and uses a lot of line.

- The manufacturer, i.e. the individual making the splice, has no effect upon the strength of threestrand splices. As discussed, if further testing demonstrates that employment of a professional splice maker does not improve the splice efficiency, then no advantage is gained by paying a more experienced person to do the splicing for you.

- The existence of a critical number of tucks or splice length was demonstrated. Below this length, the

Table 10 Effect of variation of rope diameter on the efficiency of braid-on-braid splices.

\begin{tabular}{llll}
$\begin{array}{l}\text { Rope diameter, } \\
\mathrm{mm}\end{array}$ & $\begin{array}{l}\text { Splice efficiency } \\
\text { (computer) }\end{array}$ & $\begin{array}{l}\text { Splice efficiency } \\
\text { (analogue plotter) }\end{array}$ & $\begin{array}{l}\text { Rope density } \\
\text { per unit length } \\
\left(\mathrm{kg} / \mathrm{m}^{2}\right)\end{array}$ \\
\hline 6 & 0.61 & 0.63 & 1061.03 \\
8 & 0.98 & 0.98 & 1114.08 \\
12 & 0.73 & 0.75 & 1043.34 \\
\hline
\end{tabular}


failure mode was different and the splice considerably weaker and, in the case of the braid-on-braid splice, the failure load was highly unpredictable. Above this length, an increase in length or the number of tucks caused no variation in the breaking load.

- Different diameter ropes have totally different splice efficiencies. $8 \mathrm{~mm}$ rope appears to give the highest splice efficiencies. However, it is noted that a $12 \mathrm{~mm}$ spliced rope is still significantly stronger, even if the efficiency is lower.

\section{Future work}

The present work has concentrated on knots and simple splices on standard polyester ropes of two constructions. Future work is needed to examine the strength of splices in more exotic materials, commonly used in yacht racing (Pawson (2005)). These materials, while of higher performance than standard ropes, provide significant challenges in the formation of splices and knots, due to their high material stiffness.

The formation of eye terminations by stitching and whipping needs to be investigated, together with the effect of wear, chafe and U.V. attack on the security of knots and splices.

\section{Acknowledgements}

The authors gratefully acknowledge Marlow Ropes for the baseline rope tests and New England Ropes and LIROS for information provided on rope testing techniques. Thanks are also due the Laboratory Technicians at the Department of Mechanical Engineering, University of Strathclyde and, in particular, to Mr. A. Crockett who patiently assisted throughout the testing.

\section{References}

Bailie, M. (2000) Ropes don't break! Summit, 17, 17. BS EN 892 (1996) Mountaineering equipment, Dynamic mountaineering ropes, Safety requirements and test methods.

BS EN 919 (1995) Fibre ropes for general service Determination of certain physical and mechanical properties.

Cunliffe, T. (2000) The Complete Yachtmaster, Adlard Coles Nautical, London, UK.

James, H. (2003) Splice up your life, Yachts and Yachting, 1460, 42-49.
Jarman, C. (2000) Knots in Use, Adlard Coles Nautical, London, UK.

King, C.C. (1986) Vaughan Jones and knot theory: a New Zealand mathematician unravels a new invariant which links diverse sciences in an unforeseen thread, New Zealand Mathematical Society Newsletter, 37, 28-32.

Leech, C.M. (1987) Theory and numerical methods for the modelling of synthetic ropes, Communications in Applied Numerical Methods, 3, 407-413.

Leech, C.M. (2002) The modelling of friction in polymer fibre ropes, International Fournal of Mechanical Sciences, 44, 621-643.

Leech, C.M. (2003) The modelling and analysis of splices used in synthetic ropes. In: Proceedings Mathematical, Physical and Engineering Sciences. Royal Society, London, 459, 1641-1659.

Maddocks, J.H. \& Keller, J.B. (1987) Ropes in equilibrium, Siam Fournal on Applied Mathematics, 47, 1185-1200.

Manes, A. (2002), Analysis of a Textile Rope with Analytical Models, in Nylon and Ropes for Mountaineering and Caving, 8-9 March 2002, Turin, (Italian Alpine Club Technical Committee). Online at http://www.caimateriali.org/Eventi/torino.html

Montgomery, D.C., Runger, G.C. \& Hubele, N.F. (2001). Engineering Statistics. John Wiley \& Sons, New York, US.

Pan, N. (1996) Fiber interactions in a twisted fiber structure under tension, Oceans Conference Record (IEEE), 1, 138-143.

Pan, N. \& Brookstein, D. (2002) Physical properties of twisted structures. II. Industrial yarns, cords and ropes, Fournal of Applied Polymer Sciences, 83, 610-630

Pawson, D. (2001), Pocket Guide to Knots and Splices, Chartwell Books.

Pawson, D. (2005) Rope Yarns, Yachts and Yachting, 1513, 42-46.

Phoenix, S.L. (1979) Statistical theory for the strength of twisted fiber bundles with applications to yarns and cables, Textile Research Fournal, 49, 407-423.

Saitta, A.M., Soper, P.D., Wasserman, E. \& Lein, M.L., (1999) Influence of a knot on the strength of a polymer strand, Nature, 398, No. 6731, 46-48.

Shaw, S. (2004) The Directory of Knots, Grange Books, Rochester, UK.

Schubert, P. (2002) A Number of Rope Failures amongst German and Austrian Mountaineers and Climbers since 1968, in Nylon and Ropes for Mountaineering and Caving, 8-9 March 2002, Turin, (Italian Alpine Club Technical Committee). Online at http://www.caimateriali.org/Eventi/torino.html

Wu, H.C. (1993) Frictional constraint of rope strands, Fournal of the Textile Institute, 84, 199-213. 
